\section{CONF-9510212-16}

ICANS-XiII

13th Meeting of the International Collaboration on

Advanced Neutron Sources

October 11-14, 1995

Paul Scherrer Institut, 5232 Villigen PSI, Switzerland

\title{
FEASIBILITY STUDY OF A 1-MW PULSED SPALLATION SOURCE*
}

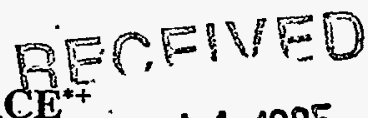

Y. Cho, Y.-C. Chae, E. Crosbie, H. Friedsam, K. Harkay, D. Horan, S. Kim,

R. Kustom, E. Lessner, W. McDowell, D. McGhee, F. Mills, H. Moe, R. Nielsen, 4 T I

G. Norek, K. J. Peterson, K. Primdahl, A. Rauchas, K. Symon, K. Thompson, and M. White

Argonne National Laboratory, Argonne, IL 60439, USA

\begin{abstract}
A feasibility study of a 1-MW pulsed spallation source based on a rapidly cycling proton synchrotron (RCS) has been completed. The facility consists of a $400-\mathrm{MeV} \mathrm{H}^{-}$linac, a $30-\mathrm{Hz}$ RCS that accelerates the $400-\mathrm{MeV}$ beam to $2 \mathrm{GeV}$, and two neutron-generating target stations. The design time-averaged current of the accelerator system is $0.5 \mathrm{~mA}$, or $1.04 \times 10^{14}$ protons per pulse. The linac system consists of an $\mathrm{H}^{-}$ion source, a 2-MeV RFQ, a 70-MeV DTL and a 330-MeV CCL. Transverse phase space painting to achieve a Kapchinskij-Vladimirskij (K-V) distribution of the injected particles in the RCS is accomplished by charge exchange injection and programming of the closed orbit during injection. The synchrotron lattice uses FODO cells of $\approx 90^{\circ}$ phase advance. Dispersion-free straight sections are obtained by using a missing magnet scheme. Synchrotron magnets are powered by a dual-frequency resonant circuit that excites the magnets at a $20-\mathrm{Hz}$ rate and de-excites them at a $60-\mathrm{Hz}$ rate, resulting in an effective rate of $30 \mathrm{~Hz}$, and reducing the required peak if voltage by $1 / 3$. A key feature of the design of this accelerator system is that beam losses are minimized from injection to extraction, reducing activation to levels consistent with hands-on maintenance. Details of the study are presented:"
\end{abstract}

\section{Introduction}

A proton synchrotron system capable of delivering $1 \mathrm{MW}$ of beam power was designed for the Intense Pulsed Neutron Source (IPNS) Upgrade Feasibility Study at Argonne National Laboratory (ANL) [1]. The RCS and associated research facilities are housed in the $50,000 \mathrm{~m}^{2}$ of space in the former 12-GeV Zero Gradient Synchrotron (ZGS) area. The ZGS . Ring Building houses a $190-\mathrm{m}$ circumference, $2-\mathrm{GeV}$ RCS. Two adjoining experiment halls house two neutron generating target stations, each serving 18 neutron beamlines and instruments. Figure 1 shows the proposed facility layout. Enclosures for the linac and low energy transport line (LET) are the only new conventional facility construction, and are also shown in Figure 1. The choice of $30 \mathrm{~Hz}$ as the repetition rate of the fast cycling synchrotron was based on preferences expressed by the users.

\section{Lattice}

Required features of the lattice are: 1) to have a large transition energy so that the lattice has a relatively large slip factor, $\left.\eta=\left|\gamma^{-2}-\gamma_{t}^{-2}\right|, 2\right)$ to have enough straight section length for a radio-

\footnotetext{
- Work supported by the U. S. Department of Energy, Office of Basic Energy Sciences under the Contract W-31109-ENG-38.

+ Keywords: Accelerator, Synchrotron, Proton 


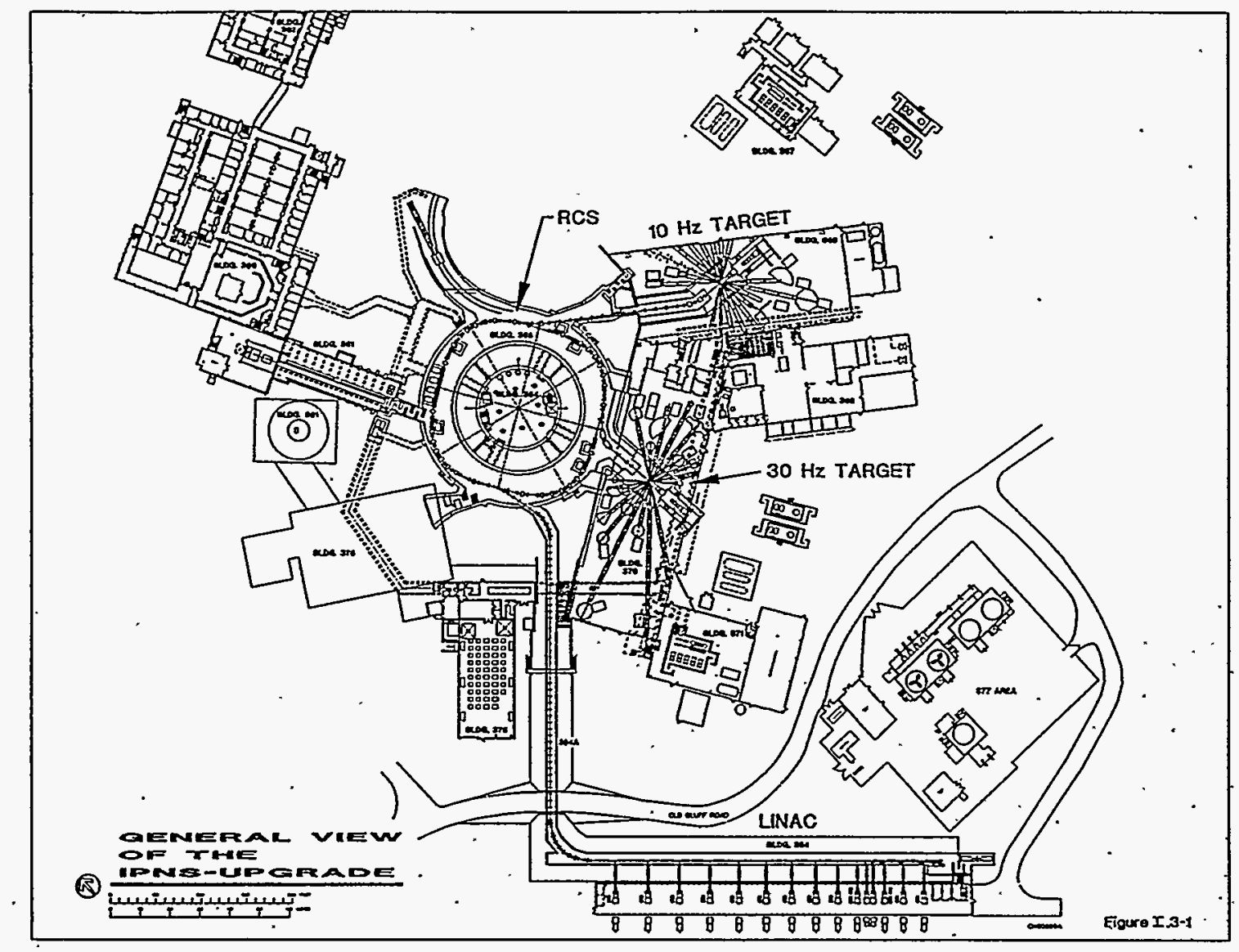

Figure 1: IPNS Upgrade Facility Layout.
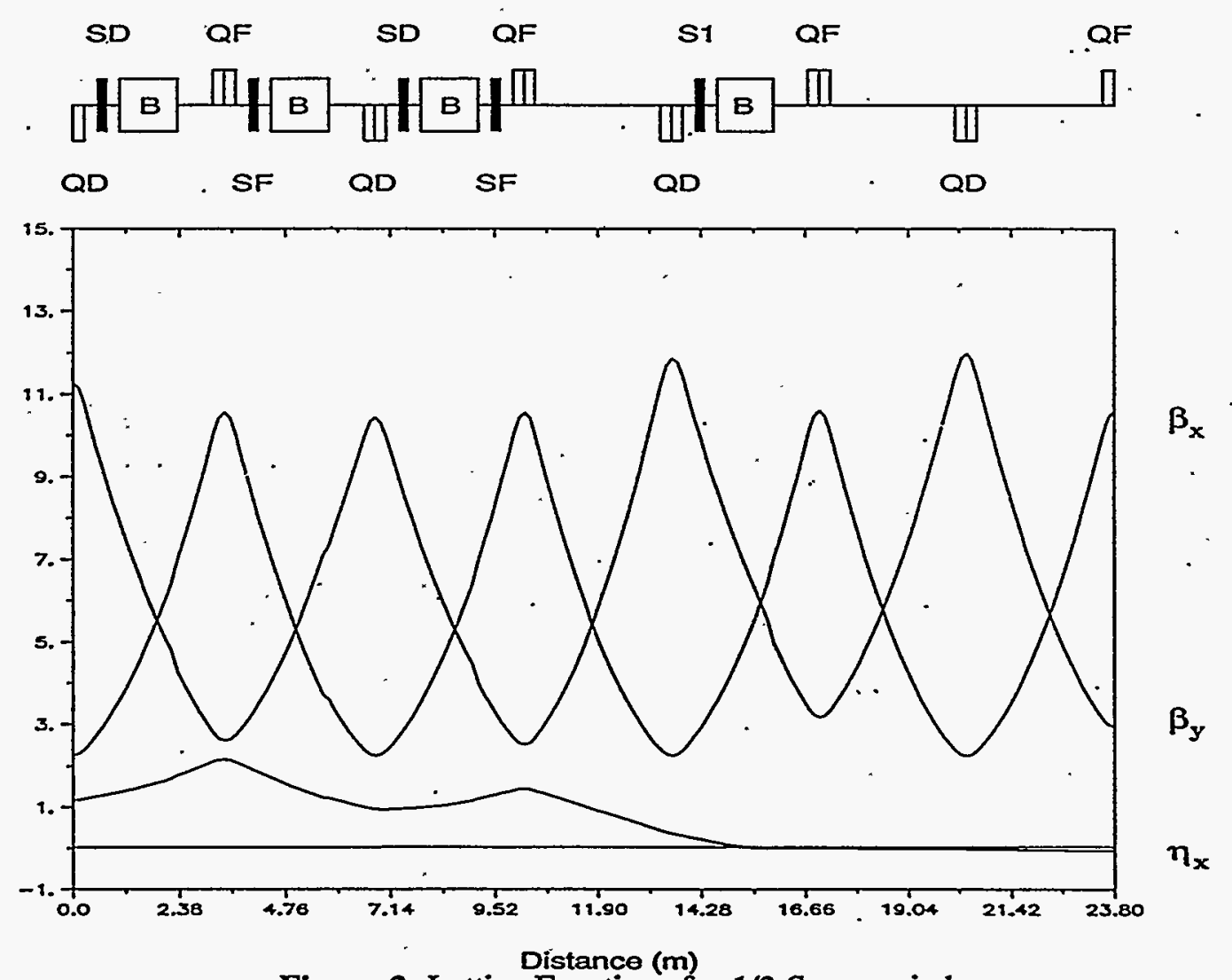

. Figure 2: Lattice Functions for 1/2 Superperiod. 
frequency cavity system that could have a total length of $20-30 \mathrm{~m}$, and 3 ) the straight sections should be dispersion-free for implementation of charge-exchange injection. Figure 2 shows $1 / 2$ of a super period with reflective symmetry at both ends. Each cell of the FODO structure has a phase advance of $\sim 90^{\circ}$ in both transverse planes. The normal cells, dispersion-suppressor cell and the straight-section cells are evident in the figure. The dispersion-suppressor cell is made by removing a dipole from a $90^{\circ}$ phase advance cell. When the vertical phase advance is slightly less than $90^{\circ}$ but the horizontal phase advance is maintained at $90^{\circ}$, the missing dipole scheme suppresses the dispersion function. An advantage of this arrangement is that the horizontal tune is about one unit higher than the vertical. The dynamic aperture study took alignment and construction imperfections into account, and the results are presented elsewhere [2]. Table 1 shows parameters of the normal cell. Table 2 is a summary of the main RCS parameters.

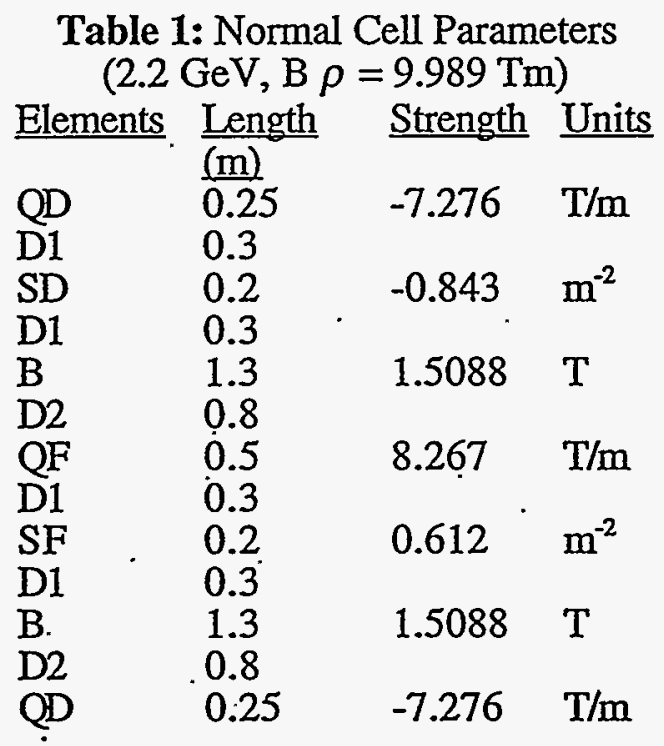

\section{Injection}

The injection energy was determined by the incoherent space charge limit of the lattice and the defined acceptance of the synchrotron. If the injected beam stack has an emittance of $375 \pi \mathrm{mm}$ $\mathrm{mr}$ in both transverse planes, the bunching factor is 0.4 , and the allowed tune shift due to space charge is 0.15 , an injection energy of $400 \mathrm{MeV}$ is sufficient to allow a time-averaged current of $0.5 \mathrm{~mA}$ with a repetition rate of $30 \mathrm{Fz}$.

The $400-\mathrm{MeV} \mathrm{H}^{-}$ion injector linac design for this feasibility study was performed by the industrial firm, AccSys Technology, Inc. The linac design specification includes: 1) an rms normalized emittance $\leq 1 \pi \mathrm{mm} \mathrm{mr}, 2$ ) an energy spread of less than $\pm 2.5 \mathrm{MeV}, 3$ ) a beam pulse length of $0.5 \mathrm{msec}$, and 4) beam chopping capability near the ion source so that the beam can be injected into a waiting synchrotron if bucket.

Phase space painting in both transverse planes is used to stack 561 turns in the synchrotron. Four bumper magnets provide radial closed orbit displacement, and both injection position and angle can be radially adjusted as shown in Figure 3. A fast vertical steering magnet allows adjustment of the vertical injection angle. Unique features of this injection system include: 1) Trajectories of incoming $\mathrm{H}^{-}$ions and of the circulating protons are combined by one of the ring focusing quadrupole magnets rather than by the customary dipole magnets. This focusing quadrupole has the added advantage that it acts as a defocusing quadrupole for the incoming $\mathrm{H}^{-}$ 
Table 2: Main Parameters of the RCS.

\begin{tabular}{|c|c|c|c|}
\hline Parameters & & Values & Units \\
\hline Circumference & & 190.4 & $\mathrm{~m}$ \\
\hline Super-periodicity & & 4 & - \\
\hline Total number of cells & & 28 & - \\
\hline Number of normal cells & & 12 & - \\
\hline Number of dispersion-suppressor cells & & 8 & - \\
\hline Number of straight-section cells & & 8 & - \\
\hline Nominal straight-section length & & 2.9 & $\mathrm{~m}$ \\
\hline Injection energy & & 400 & $\mathrm{MeV}$ \\
\hline Injection field & & 0.463 & $\mathrm{~T}$ \\
\hline Nominal extraction energy & & 2.0 & $\mathrm{GeV}$ \\
\hline Maximum design energy & & 2.2 & $\mathrm{GeV}$ \\
\hline Dipole field at $2.2 \mathrm{GeV}$ & & $1.5088^{\circ}$ & $\mathrm{T}$ \\
\hline Bending radius & & 6.6207 & $\mathrm{~m}$ \\
\hline Dipole length & & 1.3 & $\mathrm{~m}$ \\
\hline Dipole good field region & & 0.45 & $\mathrm{~m}$. \\
\hline Dipole gap height & & 0.182 & m \\
\hline Number of dipoles & & 32 & - \\
\hline Number of quadrupoles & & 56 & - \\
\hline Quadrupole length & & 0.5 & $\mathrm{~m}$ \\
\hline Quadrupole aperture radius & & 0.1185 & $\mathrm{~m}$ \\
\hline Maximum quadrupole gradient & & $8.8^{\circ}$ & $\mathrm{T} / \mathrm{m}$ \\
\hline Number of sextupoles $(F)$ & & 16 & - \\
\hline Number of sextupoles (D) & & 16 & $\therefore$ \\
\hline Number of harmonic sextupoles & & 8 & - \\
\hline Maximum sextupole strength & & 1.2 & $\mathrm{~m}^{-2}$ \\
\hline Sextupole length & & 0.2 & $\mathrm{~m}$ \\
\hline Sextupole aperture radius & & 0.13 & $\mathbf{m}$. \\
\hline Horizontal tune, $v_{X}$ & & 6.821 & - \\
\hline Vertical tune, $v_{y}$ & & 5.731 & - \\
\hline Normalized transition energy, $\gamma_{t}$ & & 5.40 & - \\
\hline Natural chromaticity, $\xi_{X}=(\Delta v)_{X} /(\Delta p / p)$ & & -7.23 & - \\
\hline Natural chromaticity, $\xi_{\mathrm{y}}=(\Delta v)_{\mathrm{y}} /(\Delta \mathrm{p} / \mathrm{p})$ & & -6.88 & - \\
\hline Maximum $\beta$ function & & 12 & $\mathrm{~m}$ \\
\hline Minimum $\beta$ function & & 2.2 & $\mathrm{~m}$ \\
\hline Maximum $\eta$ function & & 2.2 & $\mathrm{~m}$ \\
\hline Minimum $\eta$ function & & -0.06 & $\mathrm{~m}$ \\
\hline Revolution period at injection & & 890.1 & $\mathrm{nsec}$ \\
\hline Revolution period at extraction & & 665.1 & nsec \\
\hline$\dot{\mathrm{B}}_{\max }$ & & 64.5 & $\mathrm{~T} / \mathrm{sec}$ \\
\hline Maximum energy gain/turn & & 81.4 & $\mathrm{keV}$ \\
\hline
\end{tabular}


beam, and it provides an additional bend for the $\mathrm{H}^{-}$particles. There is ample separation between the incoming beam and the circulating beam. 2) Since each cell has $90^{\circ}$ phase advance, . the bumper magnets, B1 and B4, shown in Figure 3, can displace and restore the closed orbit. However, $\mathrm{B} 2$ and $\mathrm{B} 3$ are needed to adjust the injection angle of the $\mathrm{H}^{-}$ions so that $\mathrm{H}^{\circ}$ particles emerging from the stripping foil can be collected in a catcher. A discussion of the $\mathrm{H}^{-}$and $\mathrm{H}^{\circ}$ particles associated with this injection system is given in reference [3].

Using the bumper system together with the vertical steering magnet in the transport line, the injected beam can be stacked in a K-V distribution [4].

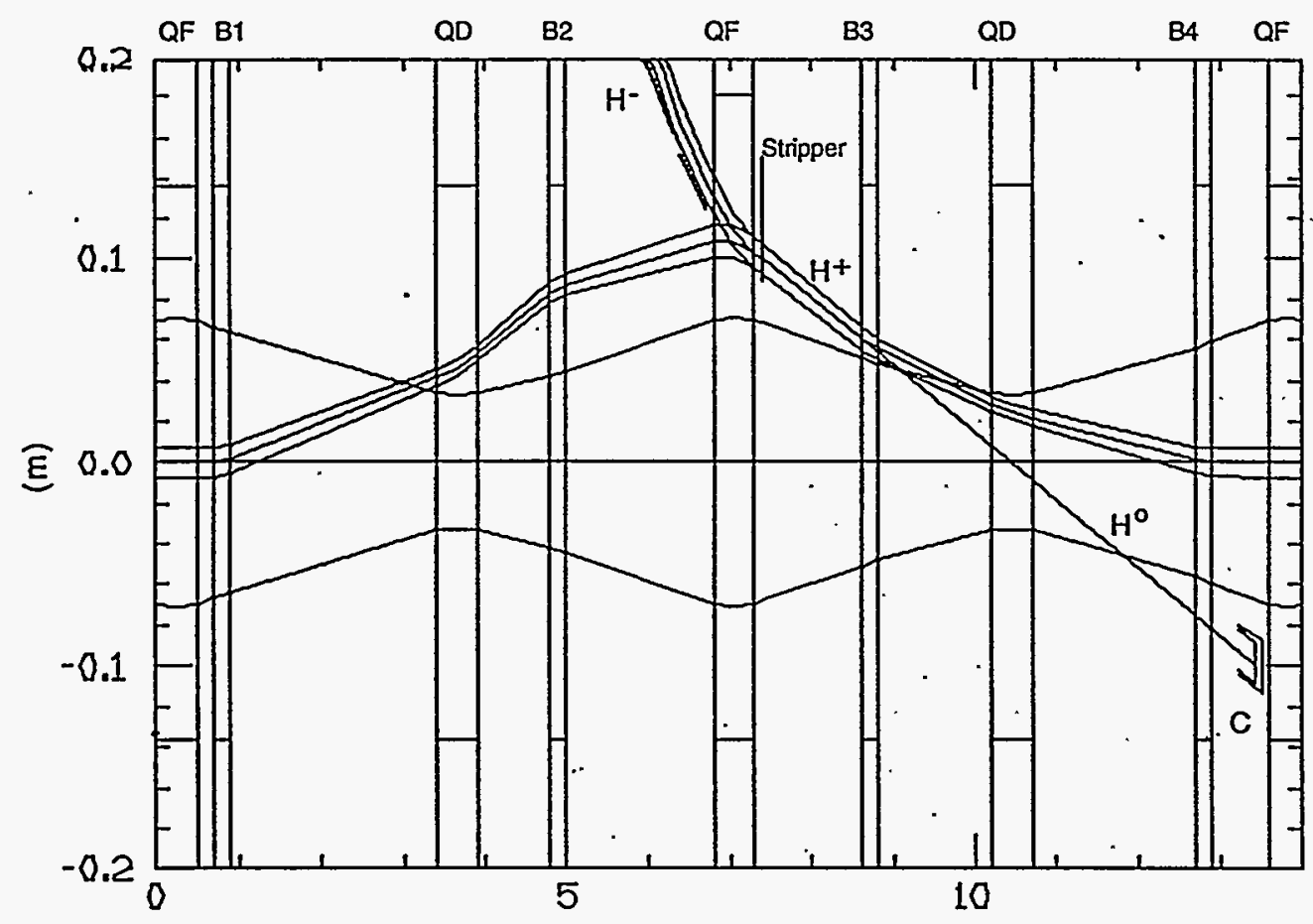

Figure 3: Bumped Orbit Injection, Showing the $\mathrm{H}^{\circ}$ Catcher (C).

\section{Rf and the Rf Voltage Program}

The RCS rf system has 10 single-ended ferrite-loaded cavities to generate the required $180 \mathrm{kV}$. There is one cavity per straight section and a total of ten straight sections dedicated for the installation of the cavities. A change in resonant frequency from 1.12 MHz at injection to 1.50 . $\mathrm{MHz}$ at extraction is accomplished by changing the dc current in the bias windings that arewound around the ferrite. A section of the rf cavity is shown in Figure 4.

A key goal of the design study was to devise an if program that prevents beam loss from injection through acceleration to extraction. The rf program was obtained using a Monte Carlo program that tracked the particles from injection to extraction. The tracking study also provided information on optimum chopping of the incoming beam. In the context of bunch rotation, chopping is related to the energy spread of the injected beam. Figure 5 shows the rf voltage program and the corresponding bucket and bunch areas. When the first turn arrives at the start of injection, $40 \mathrm{kV}$ is required to contain the linac beam that is $75 \%$ chopped (25\% removed) and has a $2.5 \mathrm{MeV}$ energy spread. The injected beam has a bunch area of $3.3 \mathrm{eV} . \mathrm{sec}$, and the 
waiting bucket has an area of $7.3 \mathrm{eV} \mathrm{sec}$, thus the initial dilution of the area is a factor of 2.2 . During injection the voltage is raised to $69 \mathrm{kV}$ to compensate for space charge effects and to give a somewhat larger bucket of $9 \mathrm{eV} \mathrm{sec}$. Soon after injection, the bunch is well formed. The $9 \mathrm{eV} \mathrm{sec}$ bucket area is maintained for the next $7.5 \mathrm{msec}$. The bucket area beyond that point in time is made larger as indicated in Figure 5, for two reasons. The first is to make the momentum spread of the circulating beam large enough to stay below instability thresholds $[5,6]$, and the second is to provide a synchrotron frequency large enough so that the particles in the bunch can follow the rapidly changing synchronous phase angle near the time of extraction.

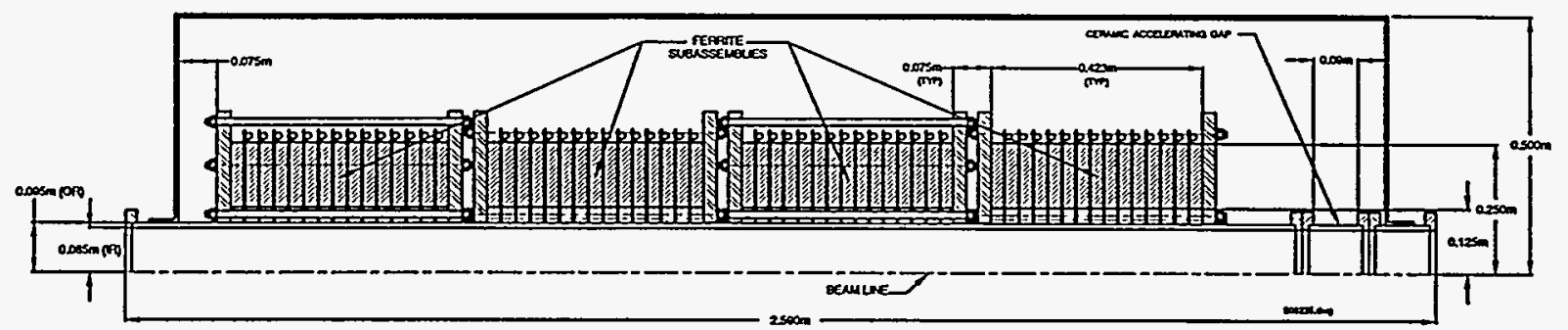

Figure 4: Quarter Sector of Single Ended Rf Cavity with Four Ferrite Sub-assemblies.

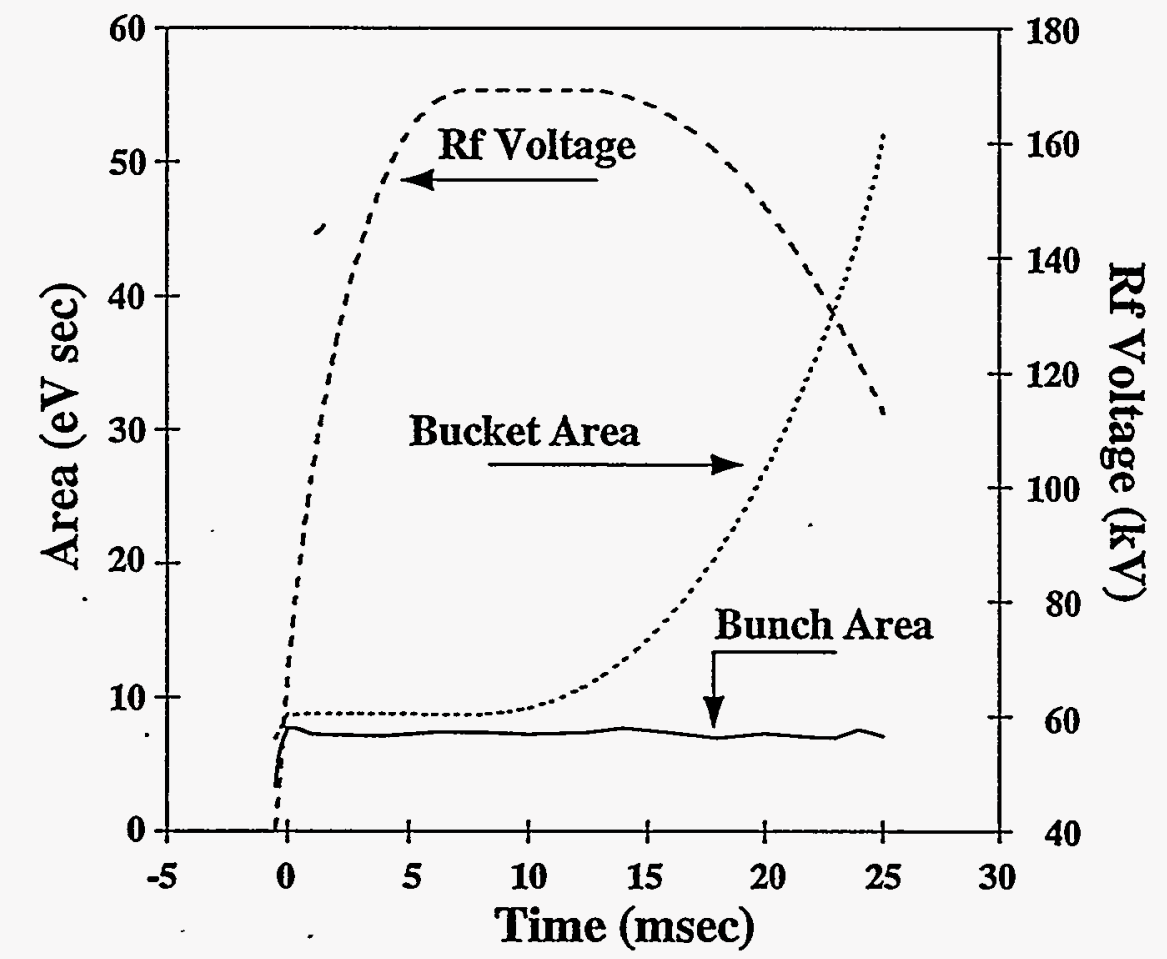

Figure 5: The Rf Voltage Program, Showing Bunch and Bucket Areas Over the Complete Cycle.

\section{Impedance and Instabilities}

The coupling impedance of the RCS is dominated by space charge which is capacitive for both the longitudinal and transverse components. The RCS operates below the transition energy, and is not expected to have longitudinal microwave instability. A detailed study of longitudinal impedance and instability was performed and results are presented in reference [5]. Similarly, the transverse impedance and instabilities were analyzed and details are presented in reference [6]. These studies showed that the machine can be operated stably. 


\section{Synchrotron Hardware}

The dipole, quadrupole, and sextupole magnets for the synchrotron are designed for a nominal beam energy of $2 \mathrm{GeV}$, but are capable of handling a maximum value of $2.2 \mathrm{GeV}$. An end view of a synchrotron quadrupole magnet is shown in Figure 6.

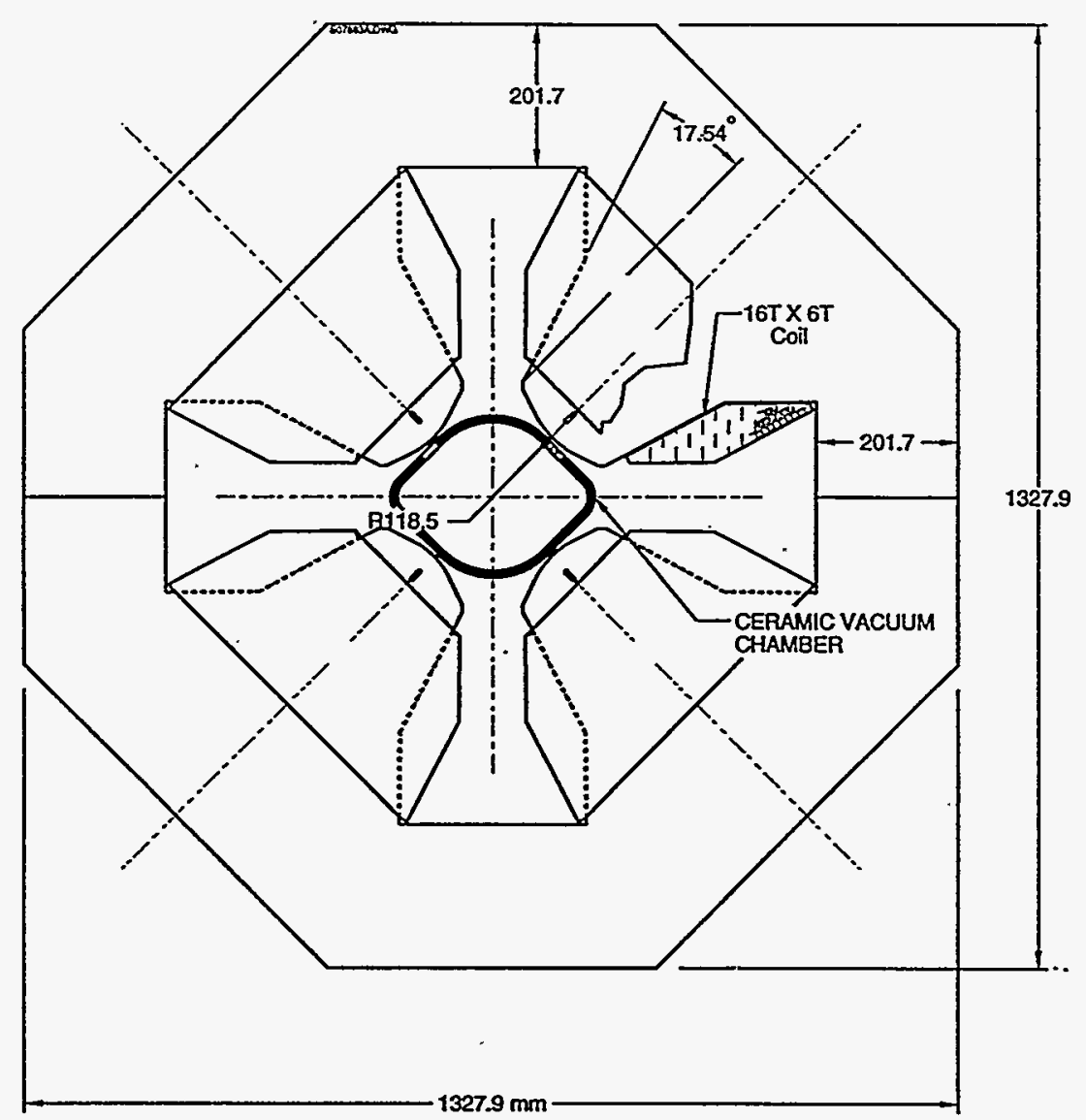

Figure 6: End View of a Synchrotron Quadrupole Magnet.

The RCS has ceramic vacuum chambers to avoid eddy currents. They are equipped with contour-following if shields constructed of conducting wires to reduce the impedance due to space charge. The system is similar to that used at the ISIS facility at Rutherford-Appleton Laboratory [7].

The RCS ring magnets are energized with dual frequency resonant power supplies that excite the ring at a $20-\mathrm{Hz}$ rate and de-energize it at a $60-\mathrm{Hz}$ rate. This method results in an overall repetition rate of $30 \mathrm{~Hz}$, and reduces the required peak if accelerating voltage by $1 / 3$. Figure 7 shows voltage and current waveforms for dual-frequency operation. Detailed descriptions of the hardware can be found in [1].

The vacuum chamber is constructed in sections made of $99.7 \%$ pure alumina ceramic. A typical quadrupole/sextupole chamber is 2.5 meters long and is constructed of individual $60-\mathrm{cm}$-long sections that are fused together. A typical cell is shown in Figure 8. 


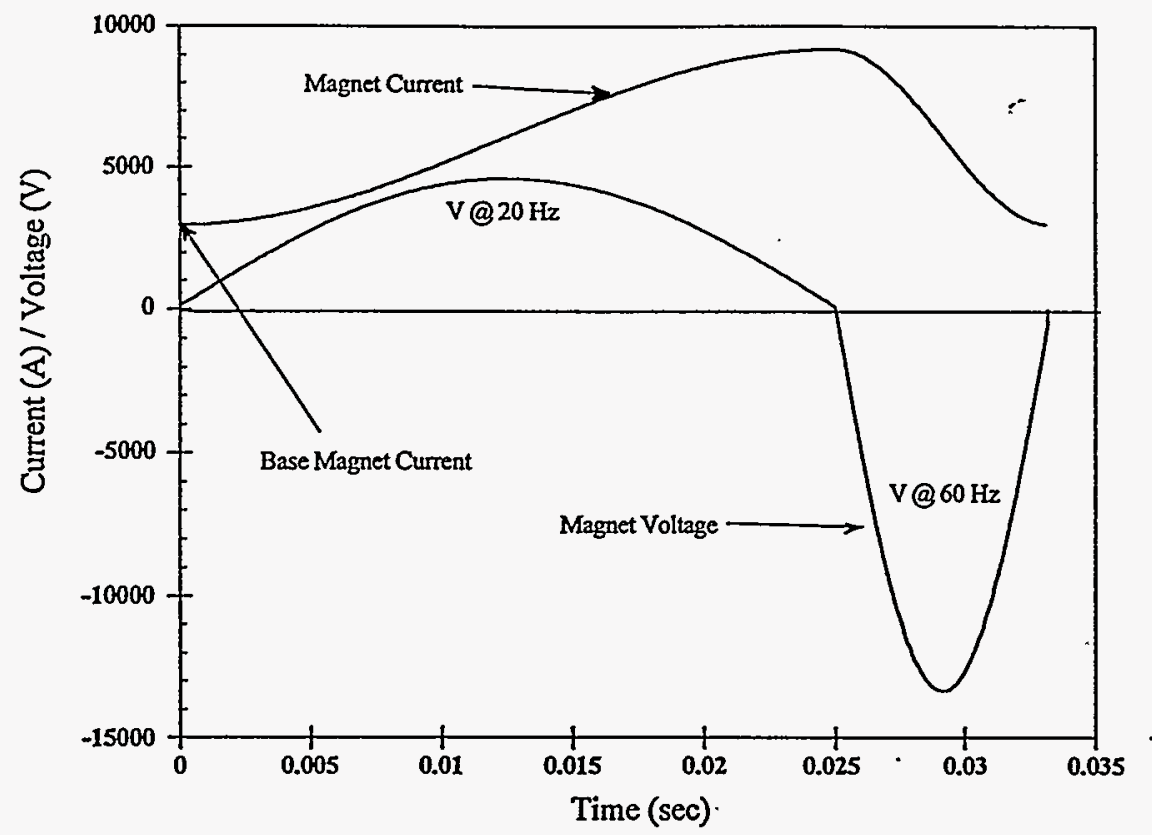

Figure 7: Dipole Magnet Current and Voltage Waveforms for Dual Frequency Operation.

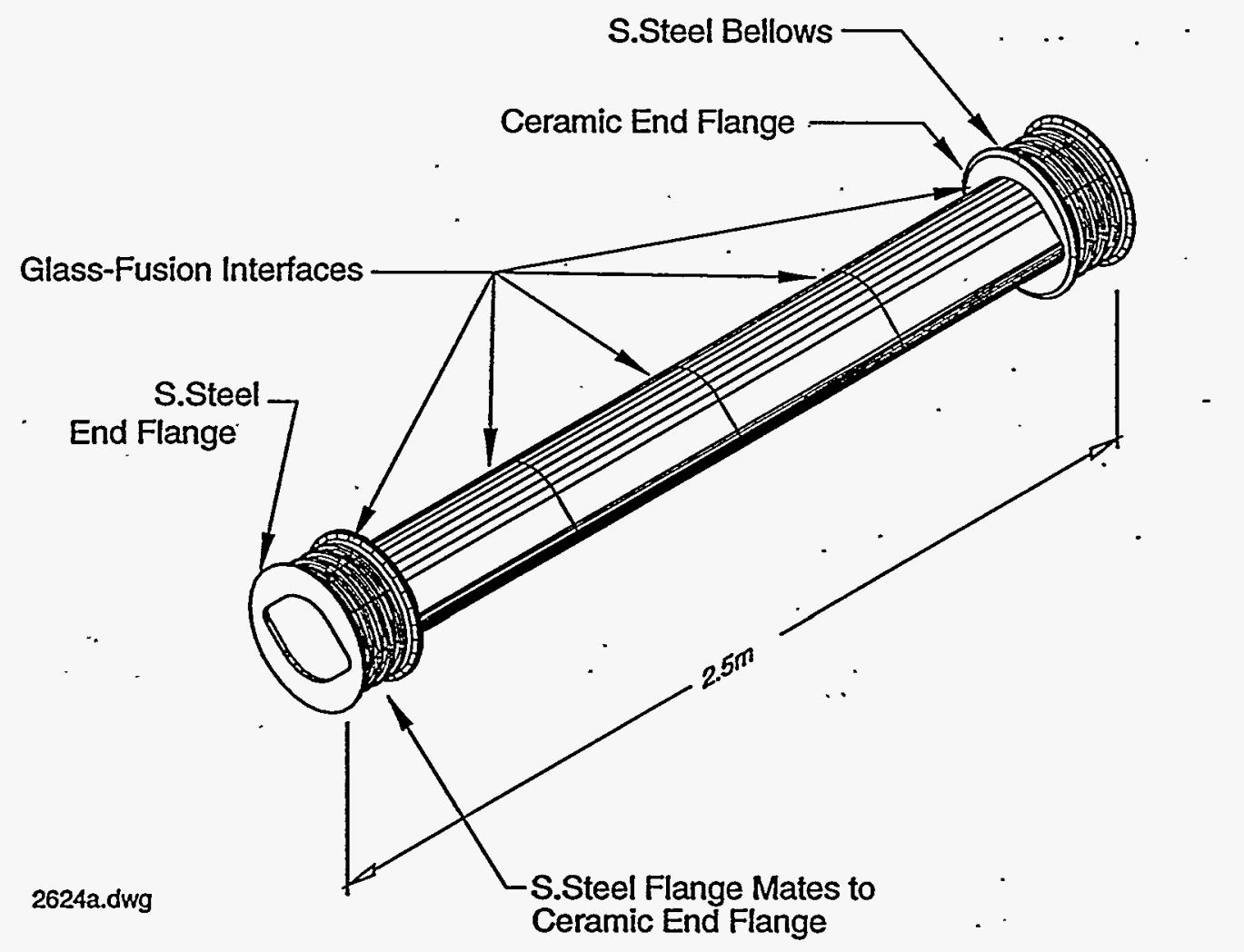

Figure 8: Typical Quadrupole/Sextupole Ceramic Chamber Cell. 


\section{Summary}

The IPNS Upgrade Feasibility Study resulted in the design of an accelerator system capable of producing $1 \mathrm{MW}$ of proton beam power, while maintaining low losses. The full power can either be delivered to one of the two neutron generating targets, or can be split between them. A scheme of phase-space painting using charge exchange allows injection of 561 turns into the machine. Low losses are critical to assure hands-on maintenance of the machine, and are achieved by providing large dynamic aperture in the transverse plane and sufficient bucket area in the longitudinal plane.

Acknowledgments

We acknowledge D. Haid for help in manipulation of computer graphics and $H$. Rihel for drawings.

\section{References}

[1] "IPNS Upgrade - A Feasibility Study," ANL Report ANL-95/13 (April, 1995).

[2] E. Lessner, Y.-C. Chae, and S. Kim, "Effects of Imperfections on Dynamic Aperture and Closed Orbit of the IPNS Upgrade Synchrotron," Proceedings of the 1995 Particle Accelerator Conference, Dallas, Texas, May 1995, to be published:

[3] Y.-C. Chae and Y. Cho, "Study of Field Ionization in Charge Exchange Injection for the IPNS Upgrade," Proceedings of the 1995 Particle Accelerator Conference, Dallas, Texas, May 1995, to be published.

[4] E. Crosbie and K. Symon, "Injecting a Kapchinskij-Vladimirskij Distribution into a Proton Synchrotron," Proceedings of the 1995 Particle Accelerator Conference, Dallas, Texas, May 1995, to be published.

[5] K. Harkay, Y. Cho, and E. Lessner, "Longitudinal Instability Analysis for the IPNS Upgrade," Proceedings of the 1995 Particle Accelerator Conference, Dallas, Texas, May 1995 , to be published.

[6] K. Harkay and Y. Cho, "Transverse Instabilities Analysis for the IPNS Upgrade," Proceedings of the 1995 Particle Accelerator Conference, Dallas, Texas, May 1995, to be published.

[7] G. H. Rees, "Status report on ISIS," in Proceedings of the IEEE Particle Accelerator Conference, Washington, DC, (March 16-19, 1987).

\section{DISCLAMER}

\footnotetext{
This report was prepared as an account of work sponsored by an agency of the United States
employeent. Neither the United States Government nor any agency any bility for the accuract warranty, express or implied, or assumes ancy thereof, nor any of their process disclosed, or represents ence herein to any specific conts that its use would not infringe privan, apparatus, product, or manufacturer, or otherwise commercial product, process, or service by ty owned rights. Refermendation, or favoring by does not necessarily constitute or imply trade name, trademark, and opinions of authors the United States Government or imply its endorsement, recomUnited States Governors expressed herein do not necessarily anyency thereof. The views -
} 